\title{
A Comparative Study: Globalization and Development of Regions of Europe, Asia Pacific, and Latin America
}

\author{
Adeola A. Adeniyi ${ }^{1} \quad$ Tej S Dhakar ${ }^{2}$ \\ 1. International Business Department, Southern New Hampshire University, 2500 North River Road, Manchester, \\ NH 03106-1045 \\ 2. Professor of Management, Southern New Hampshire University, 2500 North River Road, Manchester, NH
} 03106-1045

\begin{abstract}
Globalization is one of the most significant concepts of our time that has led to countless academic discussions and public debates. Several empirical literatures have explored how globalization has impacted developed and developing economies. It is critical to study the effects of regional globalization and the impact of different methodological perspectives. This paper examines the effects of globalization across various regions of Europe, Asia Pacific and Latin America. The secondary data used for this paper is obtained from Statista and the World Bank. The methodologies used include One-way Anova, Regression Analysis and Ancova. The findings of the Anova show how globalization significantly impacts the regions discussed in this paper. This indicates that the regions derived substantial benefits from globalization. The regression analysis results highlight that there is no relationship between globalization and democracy, and the Ancova results support that the interaction of region and democracy is not significant. We therefore conclude that the growth and development of these regions related to globalization is based on increased competition, employment, investment and capital flows, foreign trade, spread of technical know-how, spread of culture, high standard of education, and structural institutions. This paper provides a platform to better inform policy makers in these regions, as well as the world, on how the benefits of globalization lead to the expansion and growth of developed and developing countries.
\end{abstract}

Keywords: Globalization Index, Europe, Asia Pacific, Latin America, Democracy Index, Ancova

DOI: $10.7176 / \mathrm{IAGS} / 89-03$

Publication date: January $31^{\text {st }} 2021$

\subsection{Introduction}

The world has gone through increasing interconnectedness and interdependence among nations in all aspects of life and through its widespread influences on trade, investment, labor, banking and the movement of people, goods and services (Reed, 2020). Globalization has strengthened the existing ways of social interaction and has influenced human societies to transcend diverse barriers. However, the term 'globalization' continues to mean different things to different people (Kefela, 2011). Scheuerman (2010) believes that there is no unified definition of globalization and that the effects, benefits and adverse influences of globalization depend on different opinions and research findings. Ardiç (2009) sees globalization as a single phenomenon and a unified process which covers a wide range of distinct political, economic, and cultural trends across the globe while Giddens (1990) defines globalization as the intensification of world-wide social relations which link distant localities in such a way that local happenings are shaped by events occurring many miles away. Globalization has changed the world with increases in global GDP from \$63.2 trillion in 2007 to 80.9 trillion in 2017 (World Bank, 2019). World transformation continues to reflect in Asia, Europe and Latin America regions.

Recently, there has been a great controversy on the impact of globalization (Steif, 2019), hence this study seeks to investigate the effects of globalization in Europe, Asia-Pacific and Latin America region. Several studies have accessed the impact of globalization on the regions of the world, but most studies did not do a comparison on the significance of globalization on the three regions in this study together. It is a belief that globalization stimulates new technology development, particularly with the growth in FDI, and this improves economic output and makes processes more efficient. While in the average developing economy the poor as well as the wealthy benefit from globalization, in many advanced economies, globalization often has little effect on the incomes of the poor. We construct the framework of this study on the theoretical notion that economic, political and socio-cultural change associated with globalization does not mean the replacement of old practices with new ones, but the integration of old and new in forming a better way of doing business and expanding institutional structures.

Trade liberalization is one of the consideration policies of globalization and it has led to the rapid growth in emerging nations. In countries such as China and India, the number of people living on less than a dollar a day decreased by 200 million since 1980s (International Monetary Fund [IMF], 2003). The survey conducted by IMF showed that Asia-Pacific region embraced globalization and grew faster than developed countries in the 1990s. Their share in global trade rose during this period and during the second half of the 20th century, there was an increase in the scope of export growth in the region. The geographical location of the Asia-Pacific region 
characterized with the cost of a peripheral location relative to markets for inputs and outputs reduced. Transportation cost, for example, ocean freight rates were reduced and advances in information technology made communication faster and efficient (Findlay \& Williamson, 2001). Most markets in Asia expanded outside the region and this opportunity has positively affected the region's development. The relevance of growth and development of the Asian region includes a boost in life expectancy, higher literacy level, decline in infant mortality rates and a rise in real gross domestic products.

The openness of an international market in Latin America in the 1980s replaced the state control over resources, production, and services with privatization strategies. This openness deregulated and reformed financial markets, shifted inflexible labor markets to flexible ones, and moved restrictive institutions to more innovative establishments in the region. In the study by Gwynne \& Kay (2004), they discovered that globalization has limited state power and provided more technical, disciplined, and flexible national economy in the Latin America region. Over 50\% of the active populations of the seven highest-income countries in Latin America (Argentina, Brazil, Chile, Colombia, Mexico, Venezuela, and Uruguay) are involved in tertiary and quaternary employment, whereas the percentage of the labor force engaged in traditional industry continues to show a deterioration (World Bank, 2000). Globalization has also expanded the trade and investment relationships of Latin America with other regions. In addition, non-manufacturing exports such as agriculture, mining, fishing, forestry, and ranching have increased. In Asia Pacific globalization has resulted in rapidly growing international flows of goods, portfolio capital, and direct investments (Ljungwall \& $\mathrm{Sj} \tilde{\mathrm{A}} f \hat{\mathrm{A}} \boldsymbol{q b e r g}, 2005$ ). All over Latin America, globalization increases female literacy, decreases population growth with reduction in fertility rates, enhances healthcare service and improves life expectancy. Nevertheless, Latin America has been experiencing adverse events since the year 2013. The new wave of the political development in advanced economies is affecting the benefits derived from globalization. These effects have produced an increase in international interest rates, an increase in U.S protectionism, and a greater uncertainty about the change of the main economic variable (exchange rates between major currencies).

Globalization promises opportunities to those who can serve new markets or existing markets with cheaper inputs. Over the past decade, some European countries see globalization as a threat than an opportunity. The shift towards service activities in European nations is much stronger in global market compared with other regions. The effects of globalization in Europe is evident in their service sector than any other sectors of the region. There has been growth in employment for services, while employment in manufacturing has reduced. Europe remains one of the largest players in international trade with more than $15 \%$ of global exports next to U.S and China. The region's exports and services increased from about $€ 1160$ billion in 2000 to $€ 2900$ billion in 2018 with more than 80 percent of exporters in small and medium sized enterprises (European News, 2019).

There is a growing concern that countries from the Europe, Asia Pacific and Latin America regions are developed and globalization is essential in developing and emerging countries. Globalization increases international trade and the status of various underdeveloped nations by giving them a chance to showcase their goods and services in the global market. It even increases the cultural relations among nations through government policies in making the benefits of globalization more inclusive. But, has the globalization mean cut across Europe, Asia Pacific and Latin America in recent times? Is there an impact of democracy in the regions that are globalized? This study utilizes the KOF index of globalization and democracy index from Statista and World bank for the year 2019 to measure the rate of globalization and the status of democracy on Europe, Asia Pacific and Latin America regions. The methodologies used include One-way Anova, Regression Analysis and Ancova. This study tends to add to the body of knowledge by comparing how globalization has affected Europe, Asia Pacific and the Latin America regions together. With empirical results and evidence, the study will better inform government and policymakers about the recent impact of globalization in the Europe, Asia Pacific and the Latin America regions while other regions can understand the relevance of globalization in an economy.

In the following section we present review of literature, the data and method used in this study. Next is the main findings and results. Lastly, we discuss the concluding remarks of the study and the recommendations.

\subsection{Literature Review}

Several literatures show the diverse view of globalization and its development impact on developed and developing regions (Frieden \& Rogowski, 1996). Johnson (2000) claimed that globalization is based on a hierarchical system involving the control of the world polity by one single hegemon. Strange (2001) indicated that globalization is predominantly an economic transformation where "the impersonal forces of world markets" (technology, finance capital and transnational actors) are responsible for "the declining authority of states" and Harvey (1989) argued that the state is in a position to regulate the activities of corporate capital in national interest on one hand and attract them by creating a "good business climate" on the other. These lead to the empowerment of finance capital at the expense of the nation-state and organized labor. Berg \& Kruger (2003) pointed out that globalization with attractive domestic policy will enhance growth and development in nations. Shaw (2000) believed that globalization has resulted in the emergence of a "global state" while Rosenau (2001) 
linked the rise of global governance to complex relations among technology, society and the capitalist economy that undermines the capacity of nation-states within their boundaries.

The steady growth of the Europe, Asia Pacific and Latin America regions have been evident in trade openness, ease of technology transfer, and improvement in communication system. In the European News (2019), it was reported that globalization created 21.7 million jobs in the year 2000 and increased to 36 million jobs in the year 2017. According to Zhou et al. (2011) international institutions claim that globalization and free market policies would lead to rapid growth, higher employment and prosperity in nations. Globalization benefitted low income countries in the area of international trade and employment opportunities (Pillai, 2011). Jaumotte et al. (2013) found the role of technology and globalization in the rise in income inequality. Income inequality increased due to technological changes in emerging nations (LI and Zhou, 2015). In the developing regions, globalization has decreased the inequality of income (Firebaugh \& Goesling, 2004). Milanovic (2003)'s study on household surveys indicated an increase in income inequality throughout the world while Milanovic (2005) recounted that the Asia Pacific region had a decline in income inequality. Longworth (1998) acknowledged that in the long run, globalization increases domestic losers and reduces the ability of the state to reward the losers financially. The study by Siddiqui (2016) suggested that capital liberalization facilitates globalization in most of the nations since economies have become global.

Rodrik (2012) reasoned that if a country would be responsive to local democratic aspirations and demand, it would be difficult to adopt some of the globalization policies and global economic integration. In his research, he argued that globalization involves sacrificing the democratic policy of the nation-state where the government is supposed to be accountable to the populace. Cammack (1998) asserted that globalization limit state policy and encourages public policy that attract foreign investors. Boli \&Thomas (1999) acknowledged that globalization strengthens domestic institutions that support democracy since the efficient operation of the market requires an enforceable system of property rights and impartial courts, and an economic openness that compels the popularization of norms respecting the rule of law and human rights. The adverse effect of globalization will enhance lack of transparency in nations. In the study by Gill (1995) and Martin \& Schumann (1997), they observed that globalization empowers the government and multinational companies to control information given to the public. The advancement in information technology has helped the government and multinational firms to give processed information to the public and to monitor people's information closely.

An aspect of globalization is capital mobility in which advanced and emerging nations derive benefit through foreign direct investment (FDI). FDI makes it possible for nations to integrate financially and to generate jobs for both the host and home countries. In this context, Woepking (2008) emphasized that increasing liberalization of capital flow in developing countries makes their financial markets more liable to volatility. Fischer (2003) reasoned that the integration of developing economies to global markets should be materialized progressively with the establishment of necessary infrastructures otherwise their economies would be open to capital flow volatility that triggers economic crisis, loss of output and unemployment.

The impact of globalization and development in developed and developing regions generate different results in each region. Some regions which have been able to direct globalization can benefit from it and others can face economic losses (Stiglitz, 2006). The income divergence between developed and developing regions can be observed by assessing the average per capita daily incomes of regions. As seen in the World Bank global indicator of average per capita daily incomes, people of the industrialized countries earn the highest level of daily income in the world in comparison with the rest of the world. Europe, Latin America, and Asia Pacific have experienced a relative increase in their incomes despite ongoing income gap between developed and developing countries

Several theoretical and empirical studies have different conclusions about the study on globalization and development, hence this study examines globalization and development of Europe, Asia Pacific and Latin America to assess how globalization impact international and domestic development.

\subsection{Study Data and Methodology}

The globalization index is obtained from KOF Index of globalization which was developed by Dreher (2006) and updated by Dreher et al. (2008). The KOF Globalization index used as dependent variable, is internationally accepted as a general indicator of international competitiveness and integration of national economies in globalization trends. The KOF index of globalization and democracy index for the year 2019 was retrieved from Statista and World bank. The independent variable is the regions grouped into three categories. The overall index of globalization covers the economic, social, and political dimensions of globalization. Higher index denotes greater globalization. The data statistic shows 77 countries in the globalization index for the year 2019. The 2019 globalization index is used to determine the mean globalization among the three regions (Europe, Asia Pacific and America) to compare the globalization mean.

indicator The Democracy Index is an index compiled by the Economist Intelligence Unit. The Democracy index measures the states of democracy in 167 based 60 groups in five different categories: electoral process and 
pluralism, functioning of government, political participation, political culture, and civil liberties. Each country was given a score between 0 and 10 in each of the five categories, which was then averaged for an overall score. Overall scores between 8.01 and 10 are full democracies, and there are 20 of such in the world. There are ten countries with scores of 9.0 or higher; these are the most democratic nations in the world.

A One-Way Analysis of Variance using unequal sample size was conducted to evaluate the hypothesis that there is equal globalization mean among Europe, Asia Pacific and Latin America. The sample size consists of 77 countries from the three regions. We have 41 countries from Europe, 20 countries from Asia pacific and 16 countries from Latin America. Regression Analysis was utilized to assess the relationship between globalization index and democracy index. In ANOVA, we assess the effect of an experiment by comparing the amount of variability in the data that the experiment can explain against the variability that it cannot explain. If we can explain some of this 'unexplained' variance (SSR) in terms of covariates, then we reduce the error variance. ANOVA allows for an accurate assessment on the effect of testing manipulation (SSM). ANCOVA is used in this study because of the presence of covariates. The ANCOVA looks at the effects of the categorical independents on the response variable after-effects of interval covariates are controlled. The covariate, a continuous independent variable is used as control variable.

\section{ANOVA:}

Hypothesis 1

$\mathrm{H}_{0} 1$ : The globalization means of Europe, Asia pacific and Latin America are equal

$\mathrm{H}_{\mathrm{A}} 1$ : Not all the region globalization means are equal

\section{Hypothesis 2}

$$
\begin{aligned}
& H_{0}: \mu R_{1}=\mu R_{2}=\mu R_{3} \\
& H_{1}: \mu R_{1} \neq \mu R_{2} \neq \mu R_{3}
\end{aligned}
$$

$\mathrm{H}_{0}$ 2: The democracy means of Europe, Asia pacific and Latin America are equal

$\mathrm{H}_{\mathrm{A}} 2$ : Not all the region democracy means are equal

\section{Regression Analysis:}

$$
\begin{aligned}
& \mathrm{H}_{0}: \mu \mathrm{R}_{1}=\mu \mathrm{R}_{2}=\mu \mathrm{R}_{3} \\
& \mathrm{H}_{1}: \mu \mathrm{R}_{1} \neq \mu \mathrm{R}_{2} \neq \mu \mathrm{R}_{3}
\end{aligned}
$$

\section{Hypothesis}

$\mathrm{H}_{0}$ : There is no relationship between Globalization index and Democracy index

$\mathrm{H}_{\mathrm{A}}$ : There is a relationship between Globalization index and Democracy index

$$
\mathrm{Y}=\beta_{0}+\beta_{1} \mathrm{x}+\varepsilon
$$

The above equation is the linear regression model that can be used to explain the relationship between $\mathrm{x}$ and $\mathrm{Y}$, where $x=$ democracy index and $Y=$ globalization index. The slope, $\beta_{1}$ can be interpreted as the change in the mean value of $Y$ for a unit change in $x$.

\section{ANCOVA:}

\section{Hypothesis}

$\mathrm{H}_{0}$ : There is no difference in mean globalization index between the three regions after controlling for level of democracy.

$\mathrm{H}_{\mathrm{A}}$ : There is a difference in mean globalization index between the three regions after controlling for level of democracy

\subsection{Results and Findings}

Table 1: Analysis of Variance (ANOVA) for hypothesis 1

\begin{tabular}{|l|l|l|l|l|l|}
\hline GI & Sum of Square & $\mathrm{D}_{\mathrm{f}}$ & Means Square & $\mathrm{F}$ & Sig \\
\hline Between Group & 653.748 & 2 & 326.874 & 4.711 & 0.012 \\
\hline Within Group & 5134.856 & 74 & 69.390 & & \\
\hline Total & 5788.604 & 76 & & & \\
\hline
\end{tabular}

Source: The secondary data is computed in SPSS 26.

Table 1 explains the mean of globalization within the three regions (Europe, Asia Pacific and Latin America). There was a significant impact on the three regions at the $p<0.05$ level. Therefore, we reject the null hypothesis, $\mathrm{H}_{0}$ and conclude that not all the regions globalization means are equal.

Table 2: Analysis of Variance (ANOVA) for hypothesis 2

\begin{tabular}{|l|l|l|l|l|l|}
\hline DI & Sum of Square & $\mathrm{D}_{\mathrm{f}}$ & Means Square & $\mathrm{F}$ & Sig \\
\hline Between Group & 18.809 & 2 & 9.404 & 3.714 & 0.030 \\
\hline Within Group & 154.468 & 61 & 2.532 & & \\
\hline Total & 173.277 & 63 & & & \\
\hline
\end{tabular}

Source: The secondary data is computed in SPSS 26.

Table 2 indicates that the mean of democracy index within the three regions (Europe, Asia Pacific and Latin 
America) are not equal at $\mathrm{P}<0.05$. We reject the null hypothesis, $\mathrm{H}_{0}$ and conclude that not all the regions' democracy means are equal. The result shows evidence that a region can be democratized and not enjoy the full benefits of democracy.

Table 3: Regression Analysis

\begin{tabular}{|l|l|l|l|l|l|}
\hline Model & R & R Square & Adjusted R Square & F & Sig \\
\hline 1 & 0.201 & 0.040 & 0.025 & 2.601 & 0.112 \\
\hline
\end{tabular}

Predictor: Constant DI; Dependent Variable: GI

Source: The secondary data is computed in SPSS 26.

Table 3b: Coefficient

\begin{tabular}{|l|l|l|l|l|}
\hline Model & B & Std.Error & F & Sig \\
\hline Constant & 66.248 & 4.589 & 14.436 & 0.000 \\
\hline DL & 1.026 & 0.636 & 1.613 & 0.112 \\
\hline
\end{tabular}

Dependent Variable: GI

Source: The secondary data is computed in SPSS 26

Table 3 shows that there is no relationship between globalization and level of democracy in Europe, Asia and Latin America regions (i. e. $\mathrm{P}=0.112>0.05$ ). Therefore, we fail to reject the null hypothesis and conclude that there is not enough evidence. The $\mathrm{R}^{2}$ value of 0.040 shows that $4 \%$ of the variation in democracy can be explained by the globalization index. Every one percent increase in democracy index will increase the globalization score by 1.026 in all the three regions when the globalization index, $\mathrm{Y}$ is constant.

Table 4: ANCOVA (With Interaction Term)

Test of Between Subject Effect

Dependent Variable: Globalization Index

\begin{tabular}{|l|l|l|l|l|l|l|}
\hline Source & $\begin{array}{l}\text { Type III sum of } \\
\text { Square }\end{array}$ & Df & $\begin{array}{l}\text { Mean } \\
\text { Square }\end{array}$ & F & Sig & $\begin{array}{l}\text { Partial } \\
\text { Squares }\end{array}$ \\
\hline Corrected Model & 471.8869 & 5 & 94.377 & 1.348 & 0.257 & 0.104 \\
\hline Intercept & 12190.259 & 1 & 12190.259 & 174.087 & 0.000 & 0.750 \\
\hline Regions & 186.778 & 2 & 93.389 & 1.334 & 0.271 & 0.044 \\
\hline Democracy Index & 0.259 & 1 & 0.259 & 0.004 & 0.952 & 0.000 \\
\hline $\begin{array}{l}\text { Region*Democracy } \\
\text { Index }\end{array}$ & 193.93 & 2 & 96.965 & 1.385 & 0.259 & 0.046 \\
\hline Error & 4061.399 & 58 & 70.024 & & & \\
\hline Total & 349848.177 & 64 & & & & \\
\hline Corrected Total & 4533.284 & 63 & & & & \\
\hline
\end{tabular}

R squared $=0.104$ (Adjusted $\mathrm{R}$ squared $=0.027$ ).

Source: The secondary data is computed in SPSS 26.

The table 4 indicates that there is no interaction between the regions and democracy. The slopes are homogenous. The P-value of $0.259>0.05$ does not significantly predict the dependent variable. Therefore, the globalization index is not influenced by the interaction effect of the regions*democracy, hence, we conduct the ANCOVA again without the interaction term (see table 5 below).

Table 5: ANCOVA (Without Interaction Term)

Test of Between Subject Effect

Dependent Variable: Globalization Index

\begin{tabular}{|l|l|l|l|l|l|l|}
\hline Source & Type III sum of Square & Df & Mean Square & F & Sig & Partial Eta Squares \\
\hline Corrected Model & 277.956 & 3 & 92.652 & 1.306 & 0.281 & 0.061 \\
\hline Intercept & 14571.619 & 1 & 14571.619 & 205.459 & 0.000 & 0.774 \\
\hline Regions & 95.433 & 2 & 47.717 & 0.673 & 0.514 & 0.022 \\
\hline Democracy Index & 92.113 & 1 & 92.113 & 1.299 & 0.259 & 0.021 \\
\hline Error & 4255.328 & 60 & 70.922 & & & \\
\hline Total & 349848.177 & 64 & & & & \\
\hline Corrected Total & 4533.284 & 63 & & & & \\
\hline
\end{tabular}

$\mathrm{R}$ squared $=0.061$ (Adjusted $\mathrm{R}$ squared $=0.014$ ).

Source: The secondary data is computed in SPSS 26.

The table 5 indicates that there is no significant effect of democracy index between the development of the regions (Europe, Asia Pacific, Latin America) as a result of globalization. The P-value, 0.259>0.05 does not significantly predict the dependent variable. Therefore, the democracy index is not impacted by the globalization index in the regions 


\subsection{Conclusion and Recommendation}

Globalization has influenced the development of Europe, Asia Pacific and Latin America regions. It is an inevitable process for regional development and growth due to its advantageous nature. The integration of regions has improved the standard of living, the level of education, the transportation system, the transfer of technical know-how, the mobilization of capital, and the mobility of workforce around the world. Despite the negative impacts of globalization in Latin America, there are improvements in the social, economic, educational, technological, political and legal areas in the region. However, additional progress needs to be made in the same areas for the region to be able to compete effectively and efficiently worldwide. Asia Pacific region has benefited from globalization in numerous areas like healthcare service, advanced technology, high increase in export goods and services, reduction in mortality rate and increase in life expectancy. The economy of the Asia Pacific region has experienced steady growth under the influence of globalization. The size of direct foreign investment increased, and a lot of bad traditions ceased.

Additionally, globalization has also brought many drawbacks to the Asia region. Many customs and cultures such as traditional clothes have disappeared, and some language and expressions have changed. Violence and drug abuse have increased, and a lot of deadly diseases have spread under the influence of globalization. In Europe region, there are opportunities for people in developed countries to transact business across regions. Globalization benefits for consumers in this region also come from import. The consumers have access to a variety of goods sold at reasonable prices. There is an increased competitiveness and lower prices for goods and services. The level of wealth and comfort in Europe region has increased as well as the standard of living.

Policy makers and the government need to embrace the persistent nature of globalization as the best strategy for regional growth. Any region that remains non-globalized may lack growth in the long run because interdependence and integration of regions expand economic opportunities. Future researchers are encouraged to investigate the regions that are not within the context of this study to understand globalization effects on such regions.

\section{References}

Ardic, N. (2009). Friend or Foe? Globalization and Turkey at the Turn of the 21 st Century. Journal Economic and Social research.

Berg, A. \& Krueger, A. (2003). Trade, growth, and poverty: a selective survey. IMF Working Papers No.1047.

Boli, J. \& Thomas, JM. (1999). Constructing World Culture: International Nongovernmental Organizations since 1875. Stanford, CA: Stanford University Press.

Cammack, P. (1998). Globalization and the Death of Liberal Democracy. European. Review, 6(2), $249-263$.

Dreher, (2006). Does globalization affect growth? Evidence from a new index of globalization. Applied Economics 38 (10), 1091-1110.

Dreher et, al, (2008). Measuring globalization: Gauging its consequences: Springer Verlag.

Firebaugh, G.\& Goesling, B. (2004). Accounting for the Recent Decline in Global Income Inequality. American Journal of Sociology, 110(2), pp. 283-312

Fischer, S., (2003). Globalization and Its Challenges. The American Economic Review, 93 (2), pp.1-30.

Frieden, J. \& Rogowski, R. (1996). The Impact of the International Economy on National Policies: An Analytical Overview," in Keohane and Milner eds., Internationalization and Domestic Politics.

Giddens, A. (1990). The Consequences of Modernity. Stanford: Stanford University Press.

Gill, S. (1995). Globalization, Market Civilization, and Disciplinary Neoliberalism. Millennium, vol. 24, 3: pp. 399-423

Gwynne, R \& Kay, C. (2004). Latin America transformed: globalization and modernity, 2nd edn. Arnold, London.

Harvey, D. (1989). The Condition of Postmodernity. Oxford: Blackwell.

Jaumotte et al., (2013). Rising Income Inequality: Technology, or Trade and Financial Globalization?' IMF Economic Review 61(2):271-309.

Johnson, C. (2000). The Costs and Consequences of American Empire. New York:

Henry Holt.

Kefela, (2011). Driving Forces of Globalization in Emerging Market Economies Developing Countries. Asian Economic and Financial Review, 2011, vol. 1, issue 2, 83-94.

$L i$, G \& Zhou, H. (2015). Globalization of Financial Capitalism and its Impact on Financial Sovereignty. World Review of Political Economy. Vol. 6, No. 2 (Summer 2015), pp. 176-191 (16 pages).

Ljungwall, C. \& SjÃ $f \hat{A}$ đberg Ã. (2005). The Economic Impact of Globalization in Asia-Pacific - The Case of The Flying Geese. Development Economics Working Papers 22711, East Asian Bureau of Economic Research.

Longworth, R. (1998). Global Squeeze: The Coming Crisis for First-World Nations. Chicago: Contemporary 
Books.

Martin, H. \& Schumann, H. (1997). The global trap: Globalization and the assault on democracy and prosperity Leichardt: Pluto Press, pp. $x+269, \$ 24.95$ (pbk).

Milanovic, B. (2003). Can We Discern the Effect of Globalization and Income Distribution? Evidence from Household Budget Surveys. Policy Research Working Paper, No. 2876

Milanovic, B. (2005). Worlds Apart: Global and International Inequality 1950-2000. Princeton, NJ: Princeton University Press.

Pillai, (2011). Impact of Political Regime and Economic Openness on Income Inequality: A Tale of Low-Income and OECD Countries. The IUP Journal of Financial Economics IX (4):60-75.

Rodrisk, D. (2012). The Globalization Paradox: Democracy and the Future of the World Economy.

The Developing Economies 50, no.4 393-407.

Rosenau, J. (2001). "Governance in a Globalizing World." In D. Held and A. McGrew (eds), The Global Transformations Reader, Malden, MA: Polity Press.

Shaw, M. (2000). Theory of the Global State: Globality as Unfinished Revolution. Cambridge, UK: Cambridge University Press.

Scheuerman, W. (2010). Globalization. Stanford encyclopedia of Philosophy. http://plato.stanford.edu/.

Siddiqui, K. (2016d). Globalization, Trade Liberalization and the Issues of Economic Diversification in the Developing Countries. Journal of Business \& Economic Policy. ISSN 2375-0766 (Print), 2375-0774 (Online).

Strange, S. (2001). The Declining Authority of the Nation State. In D. Held and A. McGrew (eds.), The Global Transformations Reader, Malden, MA: Polity Press.

Stief, C. (2019). Globalization in the modern world. Thought Co. Retrieved from https://www.thoughtco.com/globalization-positive-and-negative-1434946

Stiglitz, J. (2008). Making Globalization Work. Economic and Social Review, 39(3), pp 171-190.

Reed, T. (2020). The Effects of the Coronavirus Pandemic in Emerging Market and Developing Economies.

Wade, J. \& Sophie, M. 2010. Europe and Management of Globalization. Journal of European Public Policy 17:3 April 2010: 299-317.

Woepking, J. (2008). International Capital Markets and Their Importance, The University of Iowa Center for International Finance and Development. [online] Available at: [Accessed 23 July 2018.

World Bank Research (2002) 'Globalization, Growth and Poverty: Building an Inclusive World Economy', The World Bank Group, http://econ.worldbank.org/prr/subpage.php?sp=2477.

Zhou et, al (2011). Impact of Globalization on Income Distribution Inequality in 60 Countries. Global Economy Journal $11(1): 1-16$.

https://www.europarl.europa.eu/news/en/headlines/economy/20190603STO53520/facts-the-benefits-ofeconomic-globalisation-in-europe.

https://www.statista.com/statistics/268168/globalization-index-by-country/ 